\title{
ACQUISITION OF LACTOSE FERMENTING PROPERTIES BY SALMONELLAE
}

\section{Role of the Medium}

\author{
S. SCHÄFLER, LEONIE MINTZER, AND CĂTĂLINA SCHÄFLER \\ “Dr. I. Cantacuzino" Institute, Bucarest, Rumania
}

Received for publication July 14, 1959

In previous work a close relationship was noticed between the fermentation of cellobiose, and other sugars with $\beta$-glucoside bonds, and the fermentation of lactose. All lactose-positive variants obtained by prolonged incubation of salmonellae in the presence of lactose simultaneously became cellobiose-positive (Schäfler and Schäfler, 1959). The cellobiose-positive variants of salmonellae in turn far more readily yielded lactose-positive variants than did the initial strains (Schäfler and Mintzer, 1959). These investigations dealt with a partially defined medium in which the fermentation of lactose offered selective advantages to the lactose-positive variants, as compared to the lactose-negative population. Attempts were made to establish to what extent these selective advantages may be present in media containing larger amounts of nutrient substances, and whether the culture medium affects the appearance of lactose-positive variants.

\section{MATERIALS AND METHODS}

Media. Koser's peptone medium: $\mathrm{NH}_{4} \mathrm{Na}$ $\mathrm{HPO}_{4} \cdot 4 \mathrm{H}_{2} \mathrm{O}, 1.5 \mathrm{~g} ; \mathrm{KH}_{2} \mathrm{PO}_{4}, 1 \mathrm{~g} ; \mathrm{MgSO}_{4} \cdot 7 \mathrm{H}_{2} \mathrm{O}$, $0.2 \mathrm{~g} ; \mathrm{H}_{2} \mathrm{O}, 1 \mathrm{~L}$; Witte peptone, $2 \mathrm{~g}$; bromothymol blue, 0.002 per cent. The same medium was used in solid form by adding $20 \mathrm{~g}$ of agar and bromothymol blue, 0.004 per cent. Hottinger's broth was prepared according to Koslov (1950). The hydrolyzate was made up of: beef meat, $1 \mathrm{~kg}$; liver, $100 \mathrm{~g}$; pancreas, $16 \mathrm{~g}$; and duodenal mucosa, $25 \mathrm{~g}$. It was diluted to $1: 3$ to $1: 4$ with beef meat infusion according to its amino nitrogen content, by adding 1 per cent $\mathrm{K}_{2} \mathrm{HPO}_{4}$ and 0.3 per cent $\mathrm{MgSO}_{4} \cdot 7 \mathrm{H}_{2} \mathrm{O}$. Final $\mathrm{pH}, 7.4$. To these media, lactose, cellobiose, sodium glutamate, and $\mathrm{NH}_{4-}$ succinate were added according to requirements. Inoculations were made into 18 by $180 \mathrm{~mm}$ tubes containing $7 \mathrm{ml}$ of each medium.

Strains. The following strains were utilized:
Salmonella stanley, Salmonella heidelberg, Salmonella glostrup, and Salmonella minnesota, as well as their cellobiose-positive and lactose-positive variants. The initial strains were supplied by the Collection of Microbial Cultures of the "Dr. I. Cantacuzino" Institute. Cellobiose-positive variants were obtained by incubating the initial strains in Koser's peptone medium supplemented with 0.5 per cent cellobiose. The cellobiose-positive variants ferment lactose in Koser's peptone medium plus 0.5 per cent lactose. The frequency of the appearance of lactose-positive variants is: S. glostrup $>S$. minnesota $>S$. heidelberg $>S$. stanley.

The lactose-positive $\left(\mathrm{L}^{+}\right)$variants were isolated and maintained on solid Koser's peptone medium with 0.5 per cent lactose. The $\mathrm{L}^{+}$variants of $S$. stanley and of $S$. heidelberg ferment lactose in 4 to 6 days, the $S$. glostrup variant in 3 to 4 days, and the $S$. minnesota variant in 5 to 7 days. A variant " $\mathrm{L}+8$ " capable of fermenting lactose within 24 to $36 \mathrm{hr}$ was obtained from the $\mathrm{L}^{+}$variant of S. glostrup by 8 passages on Koser's peptone medium plus 0.5 per cent lactose, and by subsequent selection. With $S$. heidelberg, a variant $\mathrm{L}^{+8}$, fermenting lactose in 3 days, was obtained under similar conditions.

To obtain mixed artificial cultures, various dilutions of $\mathrm{L}^{+}$cells were added to lactose-negative cultures. Dilutions of lactose-positive cells were started from 4-day cultures of $\mathrm{L}^{+}$variants in Koser's peptone medium plus lactose, which were nephelometrically brought to a turbidity of 300 million cells per ml. Plating indicated 60 to 80 per cent living cells.

Since on enriched media containing lactose the presence of lactose-positive variants often failed to be reflected by a color change of the indicator ( $\mathrm{pH}$ or redox), their existence was followed by (a) inoculating the sample into 2 tubes containing Koser's peptone medium plus 0.5 per cent lactose, 
and subsequent incubation for 14 days and (b) by plating on the same solid medium and incubating for 12 days. The determination of the proportion of lactose-positive to lactose-negative variants was made by plating on Koser's peptone medium with lactose.

Growth rates were estimated by means of a FEK photocolorimeter (wave length, $540 \mathrm{~m} \mu$ ).

The determination of lactose consumption was carried out with the Hagedorn-Jensen (1923) method-total reducing sugar given as glucose equivalent. Since glucose and galactose are taken up rapidly, practically all the reducing sugar found in lactose-positive salmonellae cultures consisted of lactose.

The qualitative determination of cellobiose in the presence of lactose was performed by a microbiological method based upon the regular appearance of cellobiose-positive mutants of $S$. heidelberg in culture media containing cellobiose. The culture in a medium containing cellobiose and lactose, in which we wished to establish the presence of cellobiose, was neutralized with $\mathrm{N} \mathrm{NaOH}$ and inactivated at $60 \mathrm{C}$ for $1 \mathrm{hr}$. One drop of sterile broth was added, and a drop of a 24-hr broth culture of $S$. heidelberg was then inoculated. The total volume of the sample was about $2 \mathrm{ml}$. After 10 days of incubation at $37 \mathrm{C}$, the appearance of cellobiose-positive variants of $S$. heidelberg was tested by plating on Koser's peptone medium plus 0.5 per cent cellobiose. If the tested culture medium contains cellobiose, cellobiosepositive colonies will appear within 36 to $48 \mathrm{hr}$. Control tubes (not inoculated previously) containing the same medium plus 0.5 per cent lactose and $0.00015 \mathrm{M}, 0.0003 \mathrm{M}$, and $0.015 \mathrm{~m}$ cellobiose, respectively, were also inoculated. This procedure enabled us to recognize a concentration of 0.00015 M cellobiose.

\section{RESULTS}

Effect of various sources of carbon and nitrogen upon the fermentation of lactose. (1) Cellobiose:In earlier experiments we found (Schäfler and Mintzer, 1959) that in Koser's peptone medium with an addition of 0.5 per cent lactose and 0.025 to 0.05 per cent cellobiose a fermentation of cellobiose takes place first. This is followed after a certain lapse of time-varying with the respective strain-by the appearance of lactose-positive variants originating from cellobiose-positive variants.
The determination of the presence of cellobiose in the culture medium has shown that a concentration of 0.05 per cent cellobiose is entirely used up within 1 to 2 days after the appearance of cellobiose-positive variants. The subsequent appearance of lactose-positive variants takes place in the absence of cellobiose. We then attempted to determine whether the presence of cellobiose would affect the appearance of lactosepositive variants. To prevent complete consumption of cellobiose we used cellobiose concentrations of $0.25,0.5,1$, and 2 per cent ( 5 tubes of 24 by $240 \mathrm{~mm}$ containing $30 \mathrm{ml}$ of culture medium). The appearance of lactose-positive variants and the presence of cellobiose in the medium were checked at intervals of $15,20,25,30$, and 40 days after the fermentation of cellobiose was completed (table 1).

Table 1 shows that in the case of $S$. stanley and $S$. heidelberg lactose-positive variants appeared only after all the cellobiose had been used. As for S. minnesota and particularly S. glostrup, their lactose-positive variants appeared in the presence of cellobiose. The determination of the proportion of lactose-positive variants of $S$. stanley and $S$. heidelberg revealed that shortly after their appearance the major part of the population was made up by these variants. Conversely, the lactose-positive variants of $S$. glostrup and $S$. minnesota represented less than 1 per cent of the entire population as long as the cellobiose was left in the tubes. After all the cellobiose had been used, the lactose-positive population developed and exceeded the cellobiose-positive population.

Similar results were obtained when lactosepositive cells were added to 48-hr cellobiosepositive cultures on media containing 0.5 per cent lactose and various concentrations of cellobiose: $10^{1}$ concentration of $\mathrm{L}^{+}$cells were eliminated regardless of strain and of cellobiose concentration; $10^{2}$ cells persisted in 40 to 60 per cent of the tubes, according to the strain; $10^{3}$ cells persisted in 70 to 85 per cent of the tubes; and $10^{4}$ cells could be found in nearly 100 per cent of all tubes, at $5,10,20,25,35$, and 45 days after being added to the culture.

The elimination of $\mathrm{L}^{+}$variants does not occur when $10^{1}$ cells are added to a culture in lactose plus cellobiose medium in which the bacteria had previously been killed by heating. In this case, the fermentation of cellobiose tock place in $48 \mathrm{hr}$. 
TABLE 1

Cellobiose uptake and development of lactose-positive variants

\begin{tabular}{|c|c|c|c|c|c|c|c|c|c|c|c|c|c|}
\hline \multirow{3}{*}{ Strain } & \multirow{3}{*}{$\begin{array}{l}\text { Period of Time } \\
\text { from Completion } \\
\text { of Cellobiose } \\
\text { Fermentation }\end{array}$} & \multicolumn{12}{|c|}{ Conc of Cellobiose (Per Cent) } \\
\hline & & \multicolumn{3}{|c|}{0.25} & \multicolumn{3}{|c|}{0.5} & \multicolumn{3}{|c|}{1} & \multicolumn{3}{|c|}{2} \\
\hline & & A & B & $\mathrm{C}$ & A & B & $\mathrm{c}$ & $\dot{A}$ & B & $\mathrm{C}$ & A & B & $\mathrm{C}$ \\
\hline \multirow{6}{*}{ Salmonella stanley } & days & & & & & & & & & & & & \\
\hline & 15 & 4 & - & 一 & - & - & - & - & - & - & - & - & 一 \\
\hline & 20 & 5 & - & - & 3 & - & - & - & - & - & - & - & - \\
\hline & 25 & 5 & 2 & - & 4 & 一 & - & - & - & - & - & - & - \\
\hline & 30 & 5 & 5 & - & 5 & 3 & - & - & - & - & - & - & - \\
\hline & 40 & 5 & 5 & - & 5 & 3 & - & - & - & - & 一 & - & 一 \\
\hline \multirow[t]{5}{*}{ Salmonella heidelberg } & 15 & 5 & - & - & 一 & - & - & - & - & - & 一 & - & - \\
\hline & 20 & 5 & 1 & - & 4 & - & - & - & - & - & - & - & - \\
\hline & 25 & 5 & 4 & - & 4 & 2 & - & - & - & - & - & - & - \\
\hline & 30 & 5 & 5 & - & 5 & 3 & - & - & - & - & - & - & - \\
\hline & 40 & 5 & $\mathbf{5}$ & - & 5 & 5 & - & - & - & - & - & - & - \\
\hline \multirow[t]{5}{*}{ Salmonella glostrup } & 15 & 5 & - & - & 2 & - & - & - & - & - & - & - & - \\
\hline & 20 & 5 & 3 & - & 4 & 2 & - & - & - & - & - & - & - \\
\hline & 25 & 5 & 4 & - & 4 & 3 & 1 & - & - & 1 & - & - & 1 \\
\hline & 30 & 5 & 5 & - & 5 & 5 & - & - & - & 2 & - & - & 3 \\
\hline & 40 & 5 & 5 & - & 5 & 5 & - & 2 & 1 & 2 & 1 & 1 & 2 \\
\hline \multirow[t]{5}{*}{ Salmonella minnesota } & 15 & 4 & - & - & - & - & - & - & - & - & - & - & - \\
\hline & 20 & 5 & 2 & - & 4 & 1 & - & - & - & - & - & - & - \\
\hline & 25 & 5 & 4 & - & 5 & 3 & - & - & - & 1 & - & - & - \\
\hline & 30 & 5 & 5 & - & 5 & 4 & - & - & - & 3 & - & - & 3 \\
\hline & 40 & 5 & 5 & - & 5 & 5 & - & 1 & 1 & 3 & - & - & 3 \\
\hline
\end{tabular}

$A=$ Number of tubes where a complete consumption of cellobiose took place. $B=$ Number of tubes showing development of lactose-positive variants and complete consumption of cellobiose. $\mathrm{C}=$ Number of tube showing growth of lactose-positive variants without complete consumption of cellobiose.

When $10^{1} \mathrm{~L}^{+}$cells were added to a cellobiosepositive culture on Koser's peptone medium containing lactose, but not cellobiose, the organisms survived indefinitely, fermenting the lactose in 7 to 14 days.

It seems that in the presence of cellobiose an antagonism exists between cellobiose-positive cells and lactose-positive cells which are cellobiose-positive at the same time. If the proportion of $\mathrm{L}^{+}$cells exceeds a certain minimal value, a state of equilibrium exists which changes in favor of the lactose-positive cells as soon as the entire amount of cellobiose has been used. The strains of $S$. glostrup and S. minnesota more frequently yield lactose-positive variants. This is probably the reason for their survival in the presence of cellobiose.

Effect of peptone concentration. By increasing the concentration of peptone in Koser's peptone medium plus 0.5 per cent lactose from 0.2 to 1 per cent, and particularly to 5 per cent, the development of lactose-positive variants from cellobiose-positive variants was delayed by 5 to 7 days, as compared with the 0.2 per cent peptone concentration. At a peptone concentration of 5 per cent, lactose-positive variants represented but a small part of the total population. This could still be noted as late as 40 days after their appearance. If $\mathrm{L}^{+}$cells were added to $48 \mathrm{-hr}$ cultures of the initial strains $10^{1}$ to $10^{4}$, they persisted in most tubes, although in a small proportion to the total population.

(2) Influence of $\mathrm{NH}_{4}$ succinate, sodium glutamate, and leucine:-In another series of experiments, the following substances were added to Koser's peptone medium containing 0.5 per cent lactose: $\mathrm{NH}_{4}$-succinate, 2 per cent; Na-glutamate, 2 per cent (easily to be utilized as sole source of carbon); and leucine, 1 per cent (in the tested strains leucine could not serve as carbon source, but was utilized as a weak source of nitrogen). Lactose-positive variants developed from cello- 
biose-positive variants 1 to 3 days later in the leucine-containing medium than in Koser's medium devoid of leucine. In most of the tubes, $10^{1} \mathrm{~L}^{+}$cells persisted when added to a 48 -hr culture of the initial strains. In the presence of succinate, lactose-positive variants appeared with a delay of 3 to 9 days. This interval varied greatly from one experiment to another. With $S$. stanley the appearance of lactose-positive variants was almost completely inhibited. By increasing the concentration of succinate to 5 per cent, the outcome of the experiments remained unchanged. In the presence of glutamate, lactose-positive variants usually appeared less frequently than in the medium containing succinate. In the tubes with glutamate a marked decrease in the total number of cells was noted during incubation, which may be responsible for the autosterilization of the culture.
By adding $10^{1}$ to $10^{4} \mathrm{~L}^{+}$cells to the initial culture containing succinate and glutamate, the former were eliminated in most of the tubes.

(3) Nutrient broth and Hottinger's broth:Nutrient broth plus 0.5 per cent lactose has an effect similar to 5 per cent peptone in Koser's medium, since $10^{1}$ to $10^{4}$ lactose-positive cells added to the culture of the initial strains are eliminated.

No lactose-positive variants resulting from cellobiose-positive variants were obtained in Hottinger's broth plus 0.5 per cent lactose. Inoculation of the initial strains into Hottinger's broth plus 0.05 per cent cellobiose and 0.5 per cent lactose yielded equally negative results.

Table 2 shows the persistence of $10^{1}$ to $10^{6} \mathrm{~L}^{+}$ cells added to 48 -hr cultures of the initial strains in Hottinger's broth plus 0.5 per cent lactose (3, $10,20,30,45$, and 60 days after their addition).

TABLE 2

Persistance of lactose-positive variants in Hottinger's medium plus 0.5 per cent lactose

\begin{tabular}{|c|c|c|c|c|c|c|c|c|c|c|}
\hline \multirow[t]{2}{*}{ Strain } & \multirow[t]{2}{*}{ Days } & \multicolumn{2}{|c|}{$\begin{array}{l}\text { No. of } \mathrm{L}^{+} \text {Cells Added } \\
\text { to Hottinger's Medium }+ \\
0.5 \% \text { Lactose (3 Tubes) }\end{array}$} & \multicolumn{7}{|c|}{$\begin{array}{c}\text { No. of } L^{+} \text {Cells Added to Hottinger's Medium }+0.5 \% \text { Lactose in the } \\
\text { Presence of Initial Strains ( } 3 \text { Tubes) }\end{array}$} \\
\hline & & $10^{1}$ & $10^{2}$ & 0 & $10^{1}$ & $10^{2}$ & $10^{3}$ & $10^{4}$ & $10^{5}$ & $10^{6}$ \\
\hline \multirow{6}{*}{$\begin{array}{l}\text { Salmonella } \\
\text { stanley }\end{array}$} & 3 & $3^{*}$ & 3 & 0 & 1 & 1 & 2 & 3 & 3 & 3 \\
\hline & 10 & 3 & 3 & 0 & 1 & 1 & 2 & 1 & 3 & 3 \\
\hline & 20 & 3 & 3 & 0 & 0 & 1 & 1 & 0 & 2 & 2 \\
\hline & 30 & 3 & 2 & 0 & 0 & 0 & 1 & 0 & 1 & 2 \\
\hline & 45 & 2 & 2 & 0 & 0 & 0 & 0 & 0 & 0 & 1 \\
\hline & 60 & 1 & 1 & 0 & 0 & 0 & 0 & 0 & 0 & 0 \\
\hline \multirow{6}{*}{$\begin{array}{l}\text { Salmonella } \\
\quad \text { heidelberg }\end{array}$} & 3 & 3 & 3 & 0 & 1 & 2 & 3 & 3 & 3 & 3 \\
\hline & 10 & 3 & 3 & 0 & 0 & 1 & 2 & 3 & 3 & 3 \\
\hline & 20 & 3 & 3 & 0 & 0 & 0 & 0 & 1 & 1 & 2 \\
\hline & 30 & 3 & 2 & 0 & 0 & 0 & 0 & 1 & 1 & 2 \\
\hline & 45 & 2 & 1 & 0 & 0 & 0 & 0 & 0 & 0 & 0 \\
\hline & 60 & 0 & 1 & 0 & 0 & 0 & 0 & 0 & 0 & 0 \\
\hline \multirow{6}{*}{$\begin{array}{l}\text { Salmonella } \\
\text { glostrup }\end{array}$} & 3 & 3 & 3 & 0 & 1 & 2 & 3 & 3 & 3 & 3 \\
\hline & 10 & 3 & 3 & 0 & 1 & 0 & 2 & 3 & 2 & 3 \\
\hline & 20 & 3 & 3 & 0 & 0 & 0 & 0 & 2 & 1 & 2 \\
\hline & 30 & 2 & 2 & 0 & 0 & 0 & 0 & 0 & 1 & 1 \\
\hline & 45 & 1 & 0 & 0 & 0 & 0 & 0 & 0 & 0 & 0 \\
\hline & 60 & 0 & 0 & 0 & 0 & 0 & 0 & 0 & 0 & 0 \\
\hline \multirow{6}{*}{$\begin{array}{l}\text { Salmonella } \\
\quad \text { minnesota }\end{array}$} & 3 & 3 & 3 & 0 & 0 & 1 & 2 & 3 & 3 & 3 \\
\hline & 10 & 3 & 3 & 0 & 0 & 1 & 2 & 1 & 3 & 3 \\
\hline & 20 & 3 & 3 & 0 & 0 & 0 & 0 & 1 & 1 & 2 \\
\hline & 30 & 3 & 3 & 0 & 0 & 0 & 0 & 1 & 0 & 2 \\
\hline & 45 & 3 & 3 & 0 & 0 & 0 & 0 & 0 & 0 & 0 \\
\hline & 60 & 1 & 2 & 0 & 0 & 0 & 0 & 0 & 0 & 0 \\
\hline
\end{tabular}

* Number of tubes from which lactose-positive cultures were obtained by seeding in Koser's peptone medium plus lactose. 
Table 2 shows that in Hottinger's broth plus 0.5 per cent lactose, added lactose-positive variants are eliminated by the initial strain. The persistence of $\mathrm{L}^{+}$variants is a function of the number of added cells. At first, a slight increase in the proportions of $\mathrm{L}^{+}$cells is noted, but these are gradually eliminated. In control tubes initially inoculated with pure cultures of lactose-positive variants, the latter give rise to lactose-negative variants which, in turn, eliminate the lactosepositive population.

The lactose-positive variant $S$. glostrup $\left(\mathrm{L}^{+8}\right)$ which ferments lactose more intensely than the corresponding $\mathrm{L}^{+}$variant, persists 10 to 15 days longer, but is eventually eliminated.

Attempts were made to prolong the duration of the presence of lactose-positive variants in mixed cultures, by adding $\mathrm{L}^{+}$cells to cultures in diluted Hottinger's broth, to older cultures in Hottinger's broth plus lactose, or to cultures in Hottinger's broth plus cellobiose and lactose. The results of adding $\mathrm{L}^{+}$variants to cultures of various age (up to 50 days) were similar to those obtained by using 48 -hr cultures. In cultures aged more than 50 days, lactose-positive variants persisted for a longer time in most experiments.

When $10^{1}$ to $10^{4} \mathrm{~L}^{+}$cells were added to $36-\mathrm{hr}$ cultures of the initial strains in Hottinger's broth plus 0.5 per cent lactose and 2 per cent cellobiose, the lactose-positive variants strongly fermented the cellobiose, and, after 1 to 2 days, the major part of the population consisted of $\mathrm{L}^{+}$cells. The cellobiose was utilized within 10 to 16 days, according to the respective strain, and, after 30 to 40 days, the $\mathrm{L}^{+}$variants were eliminated. The cellobiose-positive variants derived from the initial strains could be demonstrated as late as 60 days afterwards.

Practically indefinite persistence of $\mathrm{L}^{+}$variants was obtained by adding them to 48 -hr cultures in Hottinger's broth, diluted 1/10 with Koser's solution, plus 0.5 per cent lactose, or with 0.85 per cent $\mathrm{NaCl}$ plus 0.5 per cent lactose. In this case, lactose-positive variants are actively multiplying (particularly in Hottinger's broth diluted with Koser's solution). By adding $10^{1} \mathrm{~L}^{+}$cells, they were still present after 60 days.

Growth curves of lactose-positive variants and of initial strains on various media, and lactose uptake in these media. (1) Growth curves:-To determine whether the elimination of lactose-positive variants on a culture medium corresponds to differ- ences in their growth rate on similar media, the growth rate of the initial strains (and the lactosepositive variants) of S. stanley, S. heidelberg, and $S$. glostrup were turbidimetrically determined (for S. glostrup, both the $\mathrm{L}^{+}$variant and the $\mathrm{L}^{+8}$ variant were studied). The following media were used: Hottinger's broth; Hottinger's broth plus 0.5 per cent lactose; Hottinger's broth diluted $1 / 10$ with Koser's solution plus 0.5 per cent lactose; Kosers' solution plus 0.02 per cent peptone, and: 2 per cent $\mathrm{NH}_{4}$-succinate plus 0.5 per cent lactose; 2 per cent sodium glutamate plus 0.5 per cent lactose; and 0.5 per cent lactose.

The growth curves of cellobiose-positive variants were compared with those of lactose-positive variants in Hottinger's medium plus 0.5 per cent lactose, and in Koser's solution plus 0.02 per cent peptone, 2 per cent cellobiose, and 0.5 per cent lactose. The inoculum consisted of $0.05 \mathrm{ml}$ of 24 $\mathrm{hr}$ cultures in broth. The turbidity was determined at $7,12,24,36,48,60$, and $72 \mathrm{hr}$. The cultures in Hottinger's broth were diluted $1 / 5$ before reading. The results obtained with S. glostrup are shown in figures 1 to 4 . The data show that

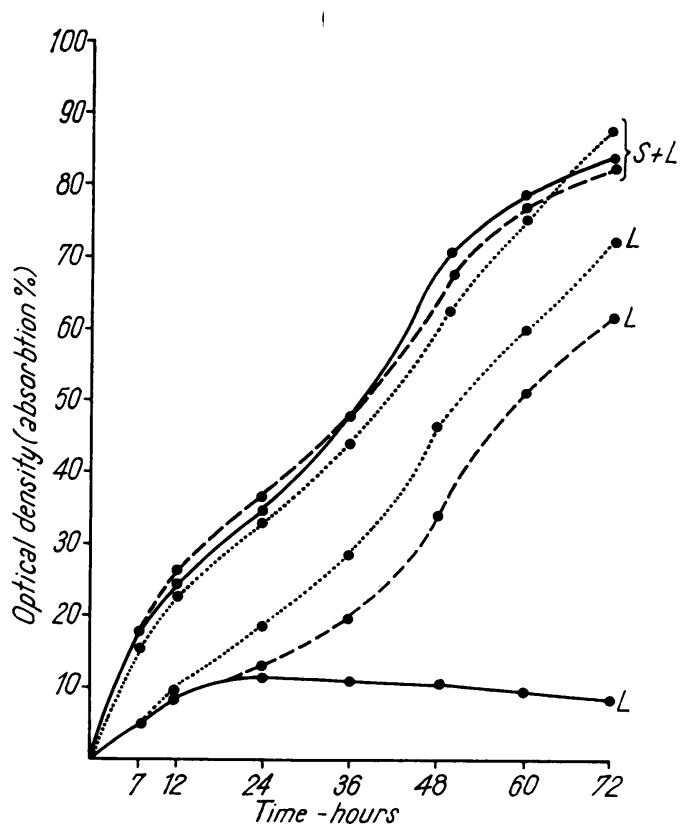

Figure 1. Salmonella glostrup, growth in presence of lactose and succinate + lactose. - - = Initial strain; $---=\mathbf{L}^{+}$variant; $\cdots=\mathbf{L}^{+8}$ variant. $L=$ Koser +0.5 per cent lactose; $S+$ $L=$ Koser +0.5 per cent lactose and 2 per cent succinate. 


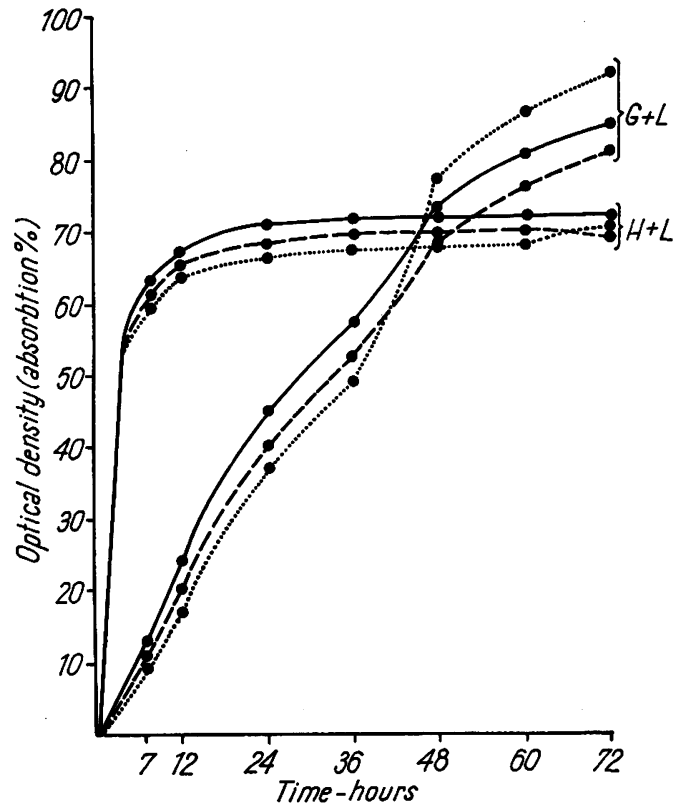

Figure 2. Salmonella glostrup, growth in presence of Hottinger's broth + lactose and glutamate. $-=$ initial strain; $---=\mathrm{L}^{+}$variant; $\cdots=\mathrm{L}^{+8}$ variant. $\boldsymbol{H}+\boldsymbol{L}=$ Hottinger's broth + 0.5 per cent lactose; $G+L=$ Koser +0.5 per cent lactose and 2 per cent glutamate.

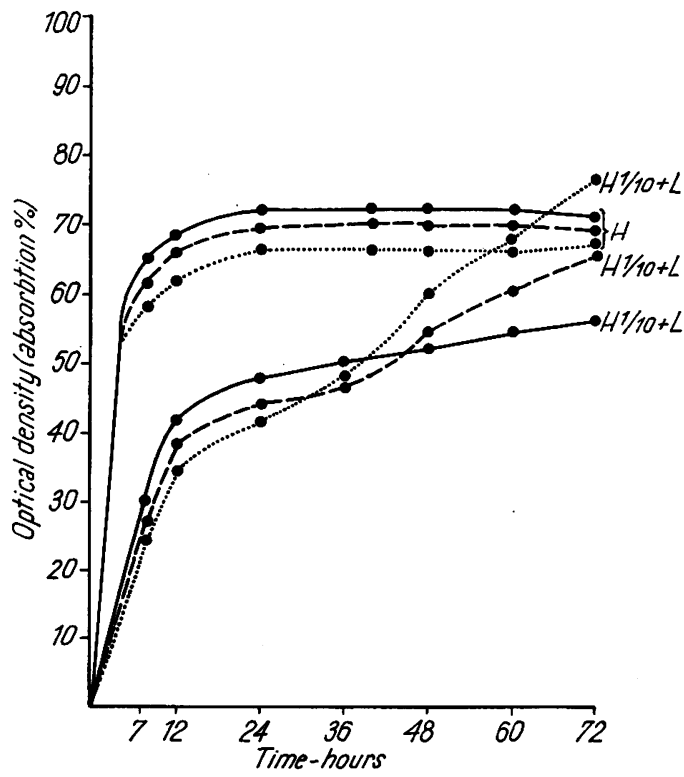

Figure 3. Salmonella glostrup; growth in presence of diluted Hottinger's broth +0.5 per cent lactose and Hottinger's broth. $-=$ Initial strain; - - = $\mathrm{L}^{+}$variant; $\cdots \mathrm{L}^{+8}$ variant. $H_{1}^{1 / 10}+\mathrm{L}=$ Hottinger's broth diluted 110 Koser +0.5 per cent lactose; $H=$ Hottinger's broth.

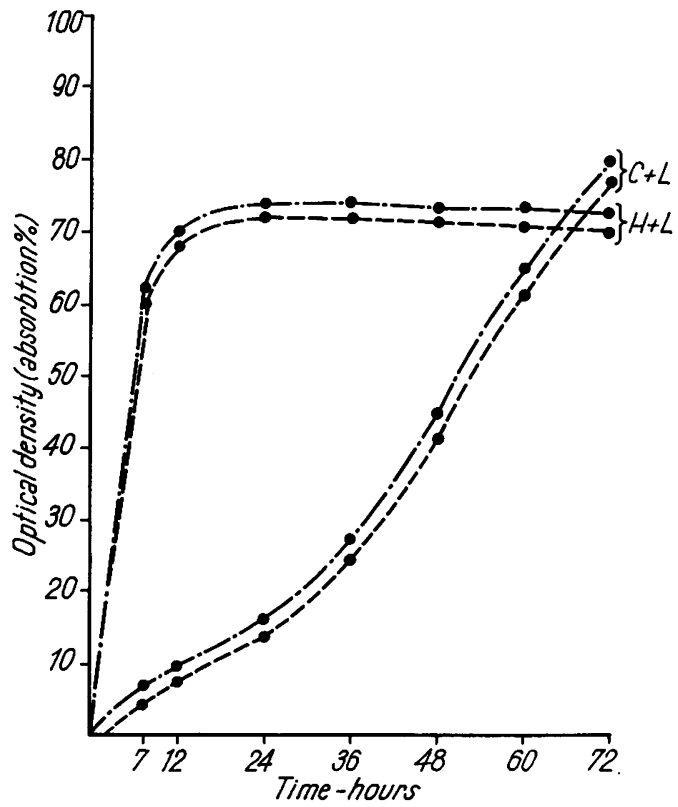

Figure 4. Salmonella glostrup growth in presence of Hottinger's broth + lactose and cellobiose. $---=\mathrm{L}^{+}$variant;..$--=$cellobiose $^{+}$variant. $H+L=$ Hottinger's broth +0.5 per cent lactose; $C+L=$ Koser +0.5 per cent lactose and 2 per cent cellobiose.

in Hottinger's broth, Hottinger's broth plus $\mathbf{0 . 5}$ per cent lactose, as well as in the presence of glutamate, the $\mathrm{L}^{+}$variant grows less easily than the initial strain. This is also noted when comparing the cellobiose-positive variant and the $\mathrm{L}^{+}$variant in Hottinger's broth plus 0.5 per cent lactose, and in Koser's medium plus cellobiose and lactose. In the presence of succinate, the $\mathrm{L}^{+}$variant grows just as well and sometimes even better, than the initial strain. In Hottinger's medium diluted $1 / 10$ with Koser's solution, the initial strain grows better within the first $24 \mathrm{hr}$. Subsequently the situation is reversed. On Koser's medium plus 0.5 per cent lactose, the growth of the $\mathrm{L}^{+}$variant is similar to that of the initial strain during the first $24 \mathrm{hr}$. After 48 to $72 \mathrm{hr}$, the growth of the lactose-positive variant becomes far more intensive.

The $\mathrm{L}^{+}$variants of $S$. stanley and $S$. heidelberg behave very much like $S$. glostrup. The $S$. glostrup $\mathbf{L}^{+8}$ variant ferments lactose rapidly, has a short induction period on Koser's medium plus 0.5 per cent lactose, and grows better than the initial strain after $48 \mathrm{hr}$ in the presence of glutamate, and after $72 \mathrm{hr}$ in the presence of succinate. In 
Hottinger's broth without lactose, the growth of the variant $\mathrm{L}^{+8}$ is weaker than that of the initial strain and of the $\mathrm{L}^{+}$variant.

The time required for a strong growth on various lactose media of the variant $L^{+8}$, as compared with that of the initial strain, may be shortened by previous cultivation on Koser's peptone medium plus 0.5 per cent lactose.

(2) Lactose uptake:-Examination of the growth curves of the lactose-positive variants and the initial strains shows that the presence of lactose fails to offer selective advantages to the growth of lactose-positive variants on certain media. Accordingly, the consumption of lactose in the same media was determined after an incubation of 3 and of 10 days at $37 \mathrm{C}$, for the initial strains as well as for the lactose-positive variants of S. heidelberg and S. glostrup (table 3).

The data show that in the presence of glutamate and succinate, the $\mathrm{L}^{+}$variants take up minimal amounts of lactose, whereas in Hottinger's broth plus 0.5 per cent lactose, the sugar is not utilized. In Hottinger's broth diluted 1/10, the lactose is used to the same extent as in Koser's peptone medium plus lactose. In 3-day cultures, however, a certain delay in the consumption of lactose could be noted.

With the $\mathrm{L}^{+8}$ variant of $S$. heidelberg the consumption of lactose is noted in the presence of glutamate, but not in the presence of succinate or in Hottinger's broth. (Glutamate identified by paper chromatography was not completely used after 10 days.) The $\mathrm{L}^{+8}$ variant of $S$. glostrup utilizes lactose, both in the presence of succinate and of glutamate, as well as in Hottinger's broth. Determination after 3 days of incubation showed that the consumption of lactose in this case takes place in the decreasing order: glutamate; Hottinger's broth diluted 1/10 by Koser's solution; succinate; Hottinger's broth.

Determinations of the presence of cellobiose and the consumption of lactose by lactose-positive variants inoculated into Koser's medium plus 0.2 per cent cellobiose and 0.5 per cent lactose were carried out on samples withdrawn daily from the 6th to 14th day. Results showed that lactose practically fails to be used as long as cellobiose is present in the medium.

In further experiments lactose consumption by $\mathrm{L}^{+}$variants of $S$. glostrup and $S$. heidelberg was estimated after a 10-day incubation in Koser's peptone medium supplemented with 1 per cent L-alanine, DL-serine, L-histidine, L-proline, Nacitrate, Na-fumarate, Na-malate, and Na-pyruvate (factors known to be directly or indirectly connected with transamination processes or Krebs cycle). The growth curves, as well as the duration of the lag phase, show particularly serine, proline,

TABLE 3

Lactose uptake by the lactose-positive variants of Salmonella heidelberg and Salmonella glostrup

\begin{tabular}{|c|c|c|c|c|c|c|}
\hline \multirow[b]{2}{*}{ Strain } & \multirow[b]{2}{*}{ incubation } & \multicolumn{5}{|c|}{ Growth Medium Plus 0.5 Per Cent Lactose } \\
\hline & & Koser & $\begin{array}{c}\text { Koser }+2 \% \\
\mathrm{NH}_{4} \text {-succinate }\end{array}$ & $\begin{array}{l}\text { Koser }+2 \% \\
\text { Na-glutamate }\end{array}$ & Hottinger & $\begin{array}{c}\text { Hottinger's } \\
\text { broth diluted } \\
\text { 1/10 with } \\
\text { Koser's } \\
\text { solution }\end{array}$ \\
\hline & days & & & & & \\
\hline \multicolumn{7}{|l|}{ S. heidelberg } \\
\hline $\mathrm{L}^{+}$ & 3 & 68 & 一 & - & - & 32 \\
\hline & 10 & 240 & 14 & 46 & 一 & 268 \\
\hline \multicolumn{7}{|l|}{ S. heidelberg } \\
\hline $\mathrm{L}^{+8}$ & 3 & 96 & 一 & 48 & 一 & 56 \\
\hline & 10 & 280 & 18 & 284 & 一 & 322 \\
\hline \multicolumn{7}{|l|}{ S. glostrup } \\
\hline $\mathbf{L}^{+}$ & 3 & 116 & - & - & - & 62 \\
\hline & 10 & 320 & 46 & 68 & - & 306 \\
\hline \multicolumn{7}{|l|}{ S. glostrup } \\
\hline $\mathbf{L}^{+8}$ & 3 & 182 & 52 & 128 & 28 & 84 \\
\hline & 10 & 478 & 426 & 462 & 204 & 482 \\
\hline
\end{tabular}

Data are given in $\mathrm{mg}$ reducing sugar per cent.

- = Lack of consumption. 
citrate, and malate to be more adequate carbon sources than lactose. Lactose consumption was also tested in the presence of 1 per cent oxyproline and leucine which cannot be used as sole earbon sources.

In the presence of alanine, serine, proline, histidine and fumarate, and citrate the lactose consumption of $\mathrm{L}^{+}$variant of $S$. glostrup was 1 to 25 per cent of the consumption in Koser's peptone medium plus lactose. It amounts to 38 per cent in the presence of pyruvate, 87 per cent in the presence of leucine, 92 per cent in the presence of malate and 94 per cent in the presence of oxyproline. Similar data were obtained in $S$. heidelberg with the exception of malate $(47$ per cent). It is clear from the above findings that all the substances readily utilizable as carbon sources, malate excepted, strongly inhibit lactose consumption.

\section{DISCUSSION}

Analysis of the above data shows that there is a close relationship between the composition of the culture medium and the capacity of lactosepositive salmonella variants to ferment lactose. The main reason for this phenomenon is the fact that the fermentation of lactose by salmonellae seems to be brought about by an adaptive enzyme. This is indicated by the growth curve of cultures in Koser's medium plus lactose, by the faster utilization of lactose by the $\mathrm{L}^{+8}$ variant of $S$. glostrup when previously cultivated in lactose, as well as by the marked interference of nutrient substances contained in the culture medium with the fermentation of lactose.

The phenomenon of inhibition of lactose fermentation in the presence of several substances may be considered as partially analogous with the diauxie phenomenon, and with the inhibition of a great number of adaptive enzymes by glucose, galactose, and several other substances (Monod, 1942; Gale, 1943; Schäfler et al., 1954; Cohn, 1957; Leiner, 1958).

Our experiments, however, have revealed some typical differences between the effect of environmental conditions upon the fermentation of lactose by salmonellae, and the effects of culture media upon the activity of the adaptive enzymes hitherto studied. The formation of adaptive enzymes is usually activated by protein hydrolyzates (Spiegelman and Halvorson, 1953), by glutamic acid (Billen and Lichtstein, 1951 ; Pinsky and Stokes, 1952), as well as by succinate (Koppel et al., 1953). The fermentation of lactose by salmonellae is inhibited by all these substances.

The differences noted could be explained by the hypothesis of different intensities of production of adaptive enzymes under the influence of the respective substrates and by the competition for metabolites from the metabolic pool.

In the case of adaptive enzymes in which the process of enzyme synthesis is sufficiently strong the metabolites required for this synthesis will be used up at a rapid rate from the metabolic pool. The introduction into the culture medium of proteins, amino acids, or other substances which may easily be transformed into essential metabolites, initially leads to a consumption of metabolites required for the formation of the enzymes involved in the assimilation of the respective substances. At the same time the assimilation of these substances ieads to an additional accumulation of metabolites in the metabolic pool. These metabolites may serve, in turn, for the active synthesis of the adaptive enzyme. That is why no inhibition of activity by amino acids has been recorded in adaptive enzymes of high intensity. (Cohn, 1957; Leiner, 1958). An inhibition of the formation of certain adaptive enzymes (i. e., $\beta$-gralactosidase of Escherichia coli) by other sugars, seems to take place rather at the stage of the induction processes than following competition for amino acids. ${ }^{1}$

The synthesis of $\beta$-galactosidase by salmonellae is far slower than that of the adaptive enzymes in which the effect of the culture medium has been studied up to the present. Therefore, the balance of metabolite distribution on media containing lactose and easily accessible nutritious substances, is shifted toward a stronger production of enzymes related to the utilization of these substrates. Succinate, citrate, fumarate, pyruvate, glutamate, as well as certain other amino acids take part, in this case, both in the plastic and in the energy metabolism. This is related to the activation of a rich enzyme system, involved in their assimilation. Owing to this fact, lactose fermentation can only take place in the absence of substrates, the assimilation of which is linked with enzymes synthesized at a faster rate than $\beta$-galactosidase. The degree of competition may

${ }^{1}$ In the case of inhibition of histidase by glucose and $m$-inositol, a competitive mechanism is, however, assumed (Neidhard and Magrasanik, 1957). 
be variable according to the composition of the medium (e. g., malate) and to the variant used.

The hypothesis of a competition of comparatively low specificity between the substances tested by us (with the exception of cellobiose) and the formation of $\beta$-galactosidase by salmonellae is supported by: (a) the diversity of the chemical structure of the inhibiting substances which have as a common feature the easy assimilation by salmonellae, and (b) the different behavior of the $\mathrm{L}^{+}$and $\mathrm{L}^{+8}$ variants of $S$. glostrup and of $S$. heidelberg. The competition for substrates almost completely disappears in the $\mathrm{L}^{+8}$ variant of $S$. glostrup which ferments lactose in 24 to $36 \mathrm{hr}$, whereas in the $\mathrm{L}^{+8}$ variant of $S$. heidelberg, which ferments lactose in 3 to 4 days, it disappears only as far as glutamate is concerned. To provide a direct proof for this hypothesis, however, a comparative study of the dynamics of the formation of the respective enzymes is required.

The effect of nonspecific competition cannot completely account for the behavior of lactosepositive variants of salmonellae, for example the more frequent appearance of lactose-positive variants in media with succinate than in those containing glutamate, or the more marked elimination of $\mathrm{L}^{+}$variants in Hottinger's broth than in Koser's medium with cellobiose. Here, a number of additional factors seem to be involved, determining to a considerable extent the mutual relations between lactose-positive and lactosenegative forms on various media (Zamenhof and Giovanni, 1958). Among these factors, an important part seems to be played by the weaker growth of lactose-positive variants as compared to the initial strains on some media on which the $\mathrm{L}^{+}$variants are not capable of utilizing lactose.

Some degree of competition is likely to exist in the case of weak fermentations. Among the mutative fermentations studied (Schäfler and Schäfler, 1959), the fermentation of raffinose and of salicin by salmonellae and that of lactose by some strains of Escherichia freundii is seen more frequently on Koser's medium plus 0.2 per cent peptone; on the other hand, the fermentation of sorbose, $\mathbf{D}$ arabinose, and cellobiose by salmonellae, and salicin by $E$. coli, occurs more frequently and often more rapidly on media containing 1 per cent peptone. Similar results were obtained in this case when using either $\mathrm{pH}$ or redox indicators.

\section{ACKNOWLEDGMENT}

Our thanks are due to Dr. C. Zilisteanu for the interest taken in this work and helpful advice in the preparation of the paper.

\section{SUMMARY}

The appearance of lactose-positive variants from cellobiose-positive variants of salmonellae was partially or totally inhibited by succinate, glutamate, cellobiose, peptone, nutrient broth, and Hottinger's broth. In the presence of these substances, lactose-positive variants were not capable of fermenting lactose, since under these circumstances they became actually lactosenegative. Through training on lactose and by selection, lactose-positive variants, which fermented lactose at a faster rate, were obtained in which the inhibition of lactose utilization by the above substances was less pronounced. The competition between the fermentation of lactose and the utilization of other substances from the culture medium, as well as the weaker growth of lactose-positive variants in conditions in which they are unable to utilize lactose, account, among other factors, for the infrequent appearance of lactose-positive variants in the usual culture media.

\section{REFERENCES}

Billen, D. and Lichstein, H. C. 1951 Nutritional requirements for the production of formic hydrogenlyase, formic dehydrogenase, and hydrogenase in Escherichia coli. J. Bacteriol., 61, 515-522.

CoHn, M. 1957 Contributions of studies on the $\beta$-galactosidase of Escherichia coli to our understanding of enzyme synthesis. Bacteriol. Rev., 21, 140-168.

Gale, E. 1943 Factors influencing the enzymic activities of bacteria. Bacteriol. Rev., 7, 139-173.

Hagedorn, H. C. AND Jensen, B. N. 1923 Zur Mikrobestimmung des Blutzuckers mittels Ferricyanid. Biochem. Z., 135, 46-58.

Koppel, J. L., Porter, C. J., and Crocker, B. F. 1953 The mechanism of the synthesis of enzymes. J. Gen. Physiol., 36, 703-722.

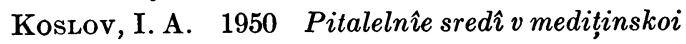
microbiologhii. Medghiz, Moskau.

Leiner, M. 1958 Die enzymatische Anpassung bei Mikro-Organismen ohne Veränderung des Erbgutes. Ergeb. Mikrobiol., 21, 35-129.

Monod, J. 1942 Recherches sur la croissance des 
cultures bactériennes. Herrmann et Cie., Paris.

Neidhard, F. C. And Magasanik, B. 1957 Effect of mixtures of substances on the biosynthesis of inductible enzymes in Aerobacter aerogenes. J. Bacteriol., 73, 260-263.

Pinsky, M. J. And Stokes, J. L. 1952 Requirements for hydrogenlyase adaptation of $E s$ cherichia coli. J. Bacteriol., 64, 151-161.

Schäfler, S. ANd Mintzer, L. 1959 Acquisition of lactose fermenting properties by Salmonellae. I. Interrelations between the fermentation of cellobiose and the fermentation of lactose. J. Bacteriol., 78, 159-163.

SChäfler, S. AND Schäfler, C. 1959 Étude comparative sur des souches d'Escherichia freundii et des souches de Salmonella. Ann. inst. Pasteur, 96, 790-794.

Schäfler, S., Voiculescu, R., Toma, E., ANd Nas L. 1954 Experimental variability in Azotobacter chroococcum (in Roumanian). Bul. ştiinţific Acad. R. P. R., 4, 571-598.

Spiegelman, H. and Halvorson, O. 1953 The nature of the precursor in the induced synthesis of enzymes. In Adaptation in microorganisms. Cambridge Univ. Press, Cambridge.

Zamenhof, S. And Giovanni, R. 1958 Study of survival of unstable strains of Escherichia coli. J. Bacteriol., 75, 514-516. 